\title{
Na Palavra vivida vive o que é a Vida da Palavra: considerações sobre a relação entre Cristologia e Pneumatologia no pensamento de Joseph Ratzinger ${ }^{1}$
}

\author{
In the Word lived lives which is the Word of \\ Life: considerations on the relationship between \\ Christology and pneumatology in the thought of \\ Joseph Ratzinger
}

Fabricio Veliq

\section{Resumo}

Esse artigo tem $o$ intuito de apresentar a relação existente entre a cristologia e a pneumatologia no pensamento de Joseph Ratzinger. Percebemos dois momentos em sua cristologia. No primeiro momento, em seu grande esforço de justificar a cristologia diante do dilema do Jesus histórico e Cristo da fé, em meados do século XX, apresenta uma excelente sistematização de seu pensamento cristológico, a partir da cristologia do Filho. Em um segundo momento, mostra-se mais voltado para o caráter experienciável da pessoa de Jesus, ou seja, a busca pelo Jesus Real, mostrado em seus três volumes de Jesus de Nazaré. O caráter pneumatológico de sua cristologia está presente nos dois momentos, visto que somente por meio do Espírito se pode tanto alcançar o Jesus Real, quanto confessar Jesus como Filho unigênito do Pai.

Palavras-chave: Cristologia. Joseph Ratzinger. Pneumatologia. Relação.

\footnotetext{
${ }^{1}$ Esse artigo é fruto do trabalho do Grupo de Pesquisa: Estudos de Cristologia, da Faculdade Jesuíta de Filosofia e Teologia de Belo Horizonte. Financiamento CAPES.
} 


\begin{abstract}
This article aims to present the relationship between Christology and pneumatology in the Joseph Ratzinger's thought. We realized two moments in his Christology: in the first one, in his great effort to justify the Christology through the historical Jesus and the Christ of faith dilema, in the mid-twentieth century, presents an excellent systematization of their Christological thought from the Christology of the Son. In a second step, it shows more focused on experienced character of the person of Jesus, that is, the search for the Real Jesus, shown in his three volumes of Jesus of Nazareth. The pneumatological character of his Christology is present on both occasions, since only through the Spirit can reach both the Real Jesus, as confessing Jesus as the only Son of the Father.
\end{abstract}

Keywords: Christology. Joseph Ratzinger. Pneumatology. Relationship.

\title{
Introdução
}

Um dos temas centrais da teologia ao longo dos séculos éa cristologia. Esse tema foi e continua sendo constantemente discutido na contemporaneidade, dado todas as implicações antropológicas e espirituais que esse tema suscita desde o século I. Diversos são os autores que falaram sobre essa temática, seja utilizando o viés teológico, seja o filosófico, seja o antropológico. Todo teólogo tem que, em algum momento, falar da pessoa do Cristo, caso queira fazer uma teologia que possa ser considerada cristã.

Traçar os caminhos da cristologia de Joseph Ratzinger se torna um grande desafio, tanto devido ao grande período de tempo em que ele escreve, quanto pelo fato de que esse tema sempre ser central e recorrente nos diversos escritos do nosso autor. Mesmo com essas características ao longo de seu percurso teológico, nossas pesquisas mostram que é possível separar seu pensamento cristológico em dois momentos, não distintos, porém complementares.

O primeiro momento se encontra a partir de 1967, onde há a sistematização de sua cristologia em seu livro Introdução ao Cristianismo. Nesse livro, apresenta os traços iniciais e de alguma forma, permanente de sua cristologia, a saber, a relação filial de Jesus com Deus.

O segundo momento se mostra a partir de seus escritos de 2005, em sua 
obra Jesus de Nazaré, onde busca caracterizar o Jesus Real, em continuidade com sua cristologia do Filho.

A pneumatologia, no entanto, não é um tema largamente desenvolvido no pensamento de nosso teólogo. Não há na obra de Ratzinger um livro que trate especificamente sobre a pneumatologia, sendo esta temática sempre tratada por nosso teólogo na relação com a cristologia. Nesse sentido, sua pneumatologia é sempre cristológica.

Nosso intuito com esse artigo é apresentar, em linhas gerais, as principais bases do pensamento cristológico e pneumatológico de nosso teólogo. Começaremos abordando aspectos de sua cristologia para, posteriormente, apresentamos sua pneumatologia cristológica.

\section{A cristologia de Joseph Ratzinger}

É importante termos em mente que Ratzinger, ao fundamentar sua cristologia nesse momento, tem em mente a discussão existente entre Bultmann e seus discípulos, que dará início à chamada "segunda busca do Jesus histórico". Bultmann afirmava que somente o Cristo da fé que deveria ser considerado importante para a fé cristã. Dessa forma, segundo seu pensamento, o Jesus histórico, com exceção ao evento da cruz, seria totalmente irrelevante para a fé. Seus discípulos, a começar por Ernst Käsemann, foram aqueles que retomaram a questão do Jesus histórico ao discordarem de seu mestre e afirmarem que o discurso pós-pascal deveria ter como base o discurso pré-pascal, de maneira que não seria possível conhecer o Cristo da fé se não houvesse um Jesus histórico. Essa identificação entre Jesus histórico e Cristo da fé na cristologia de Ratzinger é bastante perceptível como veremos adiante.

O caminho percorrido por Ratzinger em sua cristologia parte da identificação do título Cristo que é atribuído a Jesus. Sua análise parte da observação de que o título Cristo, assim como os títulos de Kaiser, Czar, César, dentre outros, são títulos que sempre exprimem uma função. Com isso em mente, nosso teólogo nos faz lembrar e pensar sobre as implicações que há em Jesus de Nazaré ser conhecido e contado como Jesus Cristo.

De início não nos parece uma informação tão importante assim, ou algo que mereça tamanha atenção a ponto de iniciar uma cristologia a partir desse caminho, contudo os olhares mais atentos podem perceber que ligar o nome à sua função traz em si algo muito mais profundo para nossa realidade. Nessa junção, segundo o pensamento de Joseph Ratzinger, está implícita a ideia de 
que não é possível separar, em Jesus de Nazaré, sua função de sua pessoa. Dessa forma, Jesus é aquilo que Ele faz, ou seja, se identifica com sua palavra de tal forma que não há como diferenciar sua obra de sua pessoa. Jesus possui essa singularidade. Ele faz e se dá, sendo sua obra total doação de si mesmo.

Essa doação é manifestada na cruz, onde há a entrega máxima em prol do outro, como nos trazem as narrativas do Evangelho. É na cruz que sua palavra, missão e existência se tornam idênticas e onde os cristãos veem claramente essas categorias todas juntas, em uma só pessoa. É no crucificado, Naquele que se entrega totalmente em prol dos outros, como consequência de sua total entrega a Deus que vemos a radicalidade de ser aquilo que diz e fazer aquilo que se é.

Seguindo essa linha de pensamento, Ratzinger proporá que todo aquele que reconhece Jesus como Cristo, e que compreende a unidade da pessoa com sua função, a identidade entre um ser humano com o ato de entrega, faz o elo entre amor e fé, pois une em uma pessoa essas duas categorias, uma vez que "acreditar num Cristo entendido dessa maneira, significa simplesmente fazer do amor o conteúdo da fé, de modo que se possa afirmar sem rodeios: amor é fé". 2

A consequência desse pensamento ratzingeriano está em perceber que a fé cristã não se torna mais, simplesmente, a aceitação de diversos dogmas cristológicos, mas trata-se da aceitação de uma pessoa, Jesus de Nazaré, aquele que se dirige ao Pai como Filho.

Ratzinger insere Jesus na linha da pergunta a respeito de Deus, ao nos mostrar que o Antigo Testamento já começa a caracterizar Deus como Deus de alguém, ou seja, o Deus dos pais de Israel. Nas diversas manifestações de Deus ao longo do texto bíblico, Ele se manifesta como o Deus de Abraão, Isaque e Jacó, ou seja, se manifesta como Deus em relação com um outro.

Jesus se enquadra nessa tradição de fé do povo de Israel. Deus, para Jesus, é Deus de alguém também, o seu Deus. Essa consciência é tão grande que, segundo Ratzinger, chega ao ponto de chamá-lo de Pai. Dessa forma, o Deus que é tão pessoal para Jesus é o mesmo Deus dos pais de Israel.

Nosso teólogo, em sua tentativa de enraizar a história de Jesus na história de Israel unida ao evangelho de João, traz Jesus como um profeta, o novo Moisés ${ }^{3}$. No judaísmo, Moisés é considerado como o maior dos profetas, visto

\footnotetext{
${ }^{2}$ RATZINGER, Joseph. Introdução ao Cristianismo. 5. ed. São Paulo: Loyola, 2012, p. 156.

${ }^{3}$ RATZINGER, Joseph. Jesus de Nazaré: da entrada em Jerusalém até a Ressurreição. São Paulo: Planeta do Brasil, 2011, p. 91.
} 
que conversava com Deus face a face, como quem conversa com um amigo. Jesus, no entanto, ultrapassa Moisés, pois em sua relação com Deus, como Filho unigênito, está em unidade com Deus.

Para Angel Cordovilla ${ }^{4}$, Ratzinger começa sua visão de Jesus a partir do título de profeta, pois quer assumir essa perspectiva histórica a partir da história narrada no Antigo Testamento (Jesus como profeta) para assim alcançar sua pessoa, ou seja, Jesus como Filho. O Filho que vive em intimidade com o Pai é o profeta que deveria vir ao mundo.

Assim como para Moisés Deus é definido a partir do homem, como Deus dos pais, assim também o Novo Testamento define Deus a partir do homem Jesus e, como consequência, a resposta à pergunta sobre quem é Deus, tem seu direcionamento para Jesus de Nazaré, aquele que chamou Deus de seu Pai.

Porém, no pensamento de nosso teólogo, o ser humano não é capaz de suportar o homem inteiramente bom, aquele que ama na verdade e que não faz mal a ninguém. Quem age assim irrita aos outros, visto estarmos em um mundo mal e que não suporta uma bondade em excesso. Essa é a realidade que chega a todo homem, visto que "o homem só é incapaz de dar um sentido satisfatório ao mundo e a si mesmo ". No Cristo crucificado vemos a manifestação mais clara dessa afirmação.

Esse homem teria a capacidade de se abrir a Deus? Nosso teólogo acredita que sim. Mesmo diante dessa constatação da maldade do homem no mundo, há nele a capacidade de se abrir a Deus e ser unido com Ele mesmo. Isso se mostra possível na pessoa de Jesus que viveu inteiramente em prol do outro e em total entrega de si ao propósito de Deus, se entregando totalmente nos braços do Pai em atitude de amor e doação.

Se esse homem, Jesus de Nazaré, foi assim, então Ratzinger propõe duas perguntas: a primeira seria: ora, a existência dessa pessoa que é total abertura para com Deus, que é totalmente Filho em sua relação com o Pai, que não somente tem amor, mas é amor, não seria idêntica ao próprio Deus? A segunda, semelhante à primeira, porém em sentido ascendente seria: ora, se esse homem, Jesus de Nazaré, é tudo aquilo que faz, assume o seu dito em ações no mundo, é um ser em total abertura para os homens sem perder-se de si, no entanto, perdendo tudo em prol dos outros, não seria esse o ser humano por excelência?

${ }^{4}$ CORDOVILLA, Ángel. "Siete tesis sobre el libro Jesús de Nazareth de Joseph Ratzinger Bento XVI". Revista de Espiritualidad 266 (2008), pp. 123-144.

${ }^{5}$ RATZINGER, Joseph. Ser Cristiano. Salamanca: Sígueme, 1967, p. 35. 
Assim, vemos que, em Jesus, Deus se torna homem, para que o homem se torne semelhante a Deus e, dessa forma, imitar a Cristo é tornar-se homem verdadeiro e assim, unir a humanidade a Deus. Nas palavras de Ratzinger:

\begin{abstract}
Seguir a Cristo significa aceitar a essência interna da cruz: o amor radical que se exprime nela, imitando assim a Deus que se revelou na cruz como aquele que se consome a si mesmo, que renuncia à sua glória, para existir por nós; que não quer governar o mundo pelo poder, mas por amor, revelando na impotência da cruz o seu poder que procede de modo tão diverso do proceder do poder dos poderosos deste mundo. Portanto, seguir a Cristo significa amar como Deus amou'.
\end{abstract}

Dessa forma, "diante da cruz de Cristo, expressão extrema da sua autodoação, não há ninguém que possa vangloriar-se a si, à própria justiça, feita por si e para si ${ }^{7 ”}$. A identidade cristã está, então, nesse não procurar por si mesmo, mas receber-se de Jesus Cristo e doar-se da mesma forma que Jesus fez, participando, assim, pessoalmente na história de Cristo até mergulhar-se totalmente Nele e partilhar seja sua morte, seja sua vida. Como Jesus fez em relação a seu Pai, aceitando aquilo que lhe estava proposto e se entregando totalmente àquele que chama de Pai para cumprir sua vontade, assim também devemos fazer se quisermos ser seus imitadores.

Nesse sentido podemos chegar à radicalidade de que é cristão todo aquele que ama como Deus ama, que se entrega como Deus se entrega. Esse pensamento implica em uma forma de agir que ultrapassa as questões religiosas e nos abre grande possibilidade de diálogo frente às religiões. Amar como Deus ama significa ser bons com os que necessitam de bondade, dar de comer aos que tem fome, amparar aos que necessitam de amparo, é deixar de considerarmos como centro do universo, como se todo o mundo tivesse que girar ao nosso redor, e reconhecermos que somos somente mais uma das criaturas de Deus a quem propôs seu amor. Esse fato, segundo nosso teólogo, equivale à revolução copernicana em seu sentido mais profundo.

No entanto, esse amor em nós é deficitário. Não conseguimos amar como Deus ama. Nesse ponto que, para Ratzinger, entra em jogo a fé. Fé de que esse déficit de amor é abundante em Jesus Cristo. Essa fé é a abertura daquele

\footnotetext{
${ }^{6}$ RATZINGER, Joseph. Dogma e anúncio. São Paulo: Loyola, 2007, p. 127.

${ }^{7}$ BENTO XVI, Papa. Os apóstolos e os primeiros discípulos de Cristo. São Paulo: Paulus, p. 135.
} 
que percebe que por suas próprias forças não conseguirá alcançar o padrão de Deus, e precisa de ajuda para isso. Essa abertura a Cristo é o que possibilita ao homem se assemelhar a Deus e conhecê-lo como Ele é.

\section{Cristologia do Filho}

Ratzinger afirma que o único título que o Jesus da história atribuiu a si mesmo foi o título de Filho e que esse remonta à vida de oração de Jesus. Jesus é aquele que chama Deus de $A b b a$. Esse termo, segundo os especialistas, é um termo de um relacionamento de intimidade (alguns dirão que é semelhante ao papai que dizemos, contudo o termo indica uma intimidade ainda mais elevada). No judaísmo do tempo de Jesus era inconcebível que alguém chamasse a Deus de "Abba".

No entanto, é justamente nesse ponto que Ratzinger fundamenta sua cristologia. É no poder chamar Deus de "Abba" que se manifesta a experiência de oração de Jesus com o Pai e assim, a existência de Jesus pode ser interpretada como totalmente relativa, sendo "a partir de" e um "ser para", ou seja, é justamente nesse ponto que Jesus se identifica com o próprio Pai.

No pensamento de Ratzinger, Jesus só pode ser entendido em relação com aquele a quem chama de Pai e a partir do qual se entende como seu Filho. Dessa forma, se torna impossível ter o Filho e não ter o Pai. Em seu pensamento "um Jesus sem Pai não tem nada, mas nada mesmo, de comum com o Jesus histórico, com o Jesus do Novo Testamento"

O Novo Testamento não conhece a Deus separado da relação de paternidade, nem sem a mediação de Jesus Cristo. É através do diálogo de Jesus com Deus, que o diálogo do homem com Deus é possível. O Deus que se manifesta no Novo Testamento, da mesma forma que se manifestava no Antigo Testamento, é um Deus que é em relação com alguém. A relação de Jesus com Deus não se mostra como a relação tradicional de seu povo, antes, se mostra como relação de intimidade ao ponto que Jesus não pode ser pensado sem o Pai, nem o Pai pode ser pensado fora da relação com Jesus.

Esse pensamento nos leva à consequência de que para que haja um conhecimento e relação com Deus, é necessário o homem Jesus. Os que pertencem a Jesus podem, assim como Ele, chamar a Deus de Pai. A fala a Felipe de João 14,9: "quem vê a mim, vê ao Pai" mostra como o acesso a

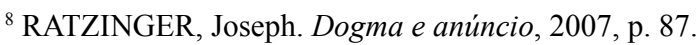


Deus passa por Jesus. Conhecer a Deus torna-se imitar a Cristo. Nas palavras de Ratzinger:

A ideia de que Deus só pode ser conhecido como Pai de Jesus Cristo, mas que assim é verdadeiramente acessível e que também Jesus só se torna compreensível como "Filho", já no Novo Testamento é radicalizada de tal modo que a dependência do conhecimento de Deus da relação Pai-Jesus, Pai-Filho não só é considerada uma forma do nosso conhecimento, um acréscimo e algo exterior (ou até irrelevante) quanto a Deus, mas é tomada como essencial para Deus mesmo. É realizada por ele e é inseparável dele, não acendendo de fora para nós. É algo próprio Dele: Deus, de fato, existe na relação Pai-Filho, ela the pertence essencialmente. Ele só pode ser apreendido como relação: desse modo, é-nos o cerne essencial e básico da doutrina da Trindade, tornando-se claro o seu conteúdo propriamente dito, central'.

Assim, no pensamento do nosso teólogo, é a partir de Jesus Cristo que vislumbramos quem é o homem e quem é Deus. Nesse sentido, fica

claro que somente aquele que se coloca por inteiro a serviço dos outros, numa atitude de desprendimento e esvaziamento total de si mesmo, transformando-se praticamente nela, é justamente o homem verdadeiro, o homem do futuro, a convergência do homem com Deus ${ }^{10}$.

É no ser chamado Filho que se mostra o caráter mais profundo do relacionamento de Jesus com o Pai e é justamente esse ser Filho que define o próprio Jesus. Ser Filho revela a proximidade de Jesus com seu Pai, uma relação diferente com qualquer outro ser humano. No pensamento de nosso teólogo, o fato de se denominar Filho não pressupõe em Jesus um aspecto de autossuficiência, mas contrariamente a isso, revela a relação total de sua existência relativa ao Pai. É nesse "ser a partir de" e "ser para" que mostra a união total de Jesus com o Pai. E, somente assim, é possível falar que ele é Filho de Deus.

Como nos diz Pablo Blanco Sarto: "Não podemos, portanto, encontrar a Jesus Cristo sem a oração, sem introduzirmos nesse diálogo contínuo do

\footnotetext{
${ }^{9}$ Ibid., pp. 87-88.

${ }^{10}$ Ibid., p. 169.
} 
Filho com o Pai ${ }^{11}$ ". É no diálogo de Jesus com o Pai, nessa relação que é possível entender como seu ser se torna serviço, como é possível seu total esvaziamento, pois está no mais íntimo de seu ser que é semelhante ao Pai.

\section{O Jesus real de Ratzinger}

Esse pode ser caracterizado como o segundo momento da cristologia ratzingeriana. A pergunta balizadora apontada por Angel Cordovilla ${ }^{12}$ poderia sintetizar muito bem o espírito dessa segunda fase: seria a análise minuciosa que destrói a figura e o mistério da pessoa de Jesus e que nos traz o acesso ao Jesus real ou seria a partir da percepção dessa figura em sua totalidade, deixando que se nos mostre ela desde de si mesma sem impor nossos pressupostos e condições de possibilidades?

A grande questão cristológica de nosso teólogo se mostra em como se achegar ao Jesus real. Afinal, os métodos históricos e científicos são incapazes de nos dar acesso a ele de forma real. A própria história nos mostra que foram diversas as tentativas de chegar à pessoa de Jesus por meio de diversas pesquisas a respeito de sua vida.

As pesquisas acerca do Jesus histórico que começaram no século XVIII e seguem até nossos dias nos mostram o quanto essa busca pode render histórias e lendas sobre sua pessoa que, ao longo do tempo, fizeram com que diversas pessoas se sentissem inseguras sobre aquilo que se deveria crer sobre a pessoa de Jesus. Segundo Ratzinger, foi Rudolf Schnackenburg quem ofereceu uma grande obra na tentativa de ajudar aos crentes que se sentiam inseguros em fundamentar a fé em Jesus Cristo, devido às diversas pesquisas históricas ${ }^{13}$. A conclusão a que chega Schnakenburg é que, através da ciência e do método histórico crítico, temos uma visão muito deficiente da figura de Jesus. Segundo Ratzinger, "Schnakenburg mostra-nos a imagem de Cristo dos Evangelhos, mas a vê construída a partir de diversas camadas da tradição, através das quais, só de longe é que é possível se perceber o Jesus real ${ }^{14}$ ". Porém, o ponto

\footnotetext{
${ }^{11}$ SARTO, Pablo Blanco. La Teología de Joseph Ratzinger: una introducción. 2. Ed. Madrid: Palabra, 2011, p. 389.

${ }^{12}$ CORDOVILLA, Ángel. "Siete tesis sobre el libro Jesús de Nazareth de Joseph Ratzinger Bento XVI". Revista de Espiritualidad 266 (2008), pp. 123-144.

${ }^{13}$ RATZINGER, Joseph (Bento XVI). Jesus de Nazaré: do batismo no Jordão à transfiguração. São Paulo: Planeta do Brasil, 2007, p. 10.

${ }^{14}$ Ibid., p.11.
} 
decisivo para Schnakenburg para a figura de Jesus é sua relação e ligação com Deus. Sem esse fundamento, a pessoa de Jesus seria totalmente inexplicável.

É nessa linha que o primeiro volume da obra Jesus de Nazaré escrito por Ratzinger segue: "ele vê Jesus a partir da sua comunhão com o Pai, a qual é o centro autêntico da sua personalidade, sem a qual nada se pode compreender e a partir da qual Ele se torna presente para nós hoje $\mathrm{e}^{15}$ ".

Pensando dessa forma, tentar chegar ao Jesus real pelas buscas do Jesus histórico seria como o tirar a casca de uma cebola. A cada pedaço que se tira, mas a cebola deixa de ser uma cebola, sobrando, no final, algo muito diferente da cebola que tínhamos inicialmente. Assim, com a pesquisa em busca do Jesus histórico, na tentativa de encontrar o Jesus real, o resultado foi o encontrar de um Jesus totalmente irreal, que nada tem a ver com o Jesus anunciado nos evangelhos. Esta constatação se mostra de maneira bem perceptível nos estudos conduzidos pela "primeira busca do Jesus histórico", onde Jesus, em certo momento, como proposto por Kalthoff, se tornou um receptáculo onde qualquer teólogo poderia derramar suas ideias, sendo, no final do século XIX, "uma figura projetada pelo racionalismo, dotado de vida pelo liberalismo, e revestido pela moderna teologia com uma vestimenta histórica ${ }^{16 "}$

Ratzinger busca a figura de Jesus ao longo dos quatro evangelhos. Uma figura mais lógica e compreensível que as reconstruções que tivemos que lidar ao longo da história, tais como a burguesa, liberal, revolucionária, dentre outras. No entanto, não rechaça a pesquisa histórica feita no intuito de definir melhor o contexto que Jesus viveu, suas palavras e atos ao longo de sua vida. Ao mesmo tempo, tem plena consciência que, mesmo cercada de importância, a pesquisa histórica não dá acesso à pessoa e ao mistério de Jesus Cristo.

Ratzinger tem claro que buscar o Jesus real não é possível somente pela aproximação histórica e científica. Para alcançá-lo, a fé se torna fator imprescindível. Tanto uma fé na sua perspectiva horizontal, tendo Jesus como herdeiro e consumador das promessas do Antigo Testamento, como uma fé em uma dimensão vertical, em relação a Deus.

O mistério permanece mesmo com toda a ciência e a pesquisa histórica. A vida histórica de Jesus nos dá acesso ao Cristo da fé e ao Jesus real somente através do mistério. Esse mistério traz para nós a inseparabilidade entre o Jesus histórico e o Cristo da fé. É ele também que nos dá acesso à própria fé

\footnotetext{
${ }^{15}$ Ibid., p.11.

${ }^{16}$ SCHWEITZER, Albert. A busca do Jesus histórico. São Paulo: Novo Século, 2005, p. 479.
} 
em Cristo, que, como pontua bem Cordovilla, e nesse sentido concordamos com ele, se situa além do fato histórico e do dogma.

Mesmo a história sendo um dado importante no discurso ao longo da vida de Ratzinger, ele tem claro para si que o passo de fé não vem pela questão histórica, mas antes pela experiência pessoal que cada pessoa tem com Cristo. É no se aproximar de Cristo, contemplado com os olhos da fé, que o homem alcança o toque de Jesus.

No pensamento de Ratzinger, o Jesus da história e o Cristo da fé não podem se separar. Contudo, esse Jesus da história que é o Cristo da fé dos cristãos tem que se tornar, para cada crente, um Jesus real, que vem ao encontro daquele que se aproxima Dele.

Se não for dessa forma, cairemos somente em fatos históricos justificados por uma posição dogmática por um lado, ou em seu contrário, uma posição meramente fideísta que não se preocupa em dar razão de sua fé diante da sociedade.

\section{A pneumatologia cristológica de Joseph Ratzinger}

Como dissemos no início de nosso artigo, não há nenhum livro específico de Ratzinger que trate somente o tema da pneumatologia, sendo essa sempre colocada em relação com sua cristologia. Nesse sentido, podemos dizer que sua pneumatologia é cristológica.

Ratzinger tem claro que ao longo de toda tradição cristã, sem dúvida, a pessoa do Espírito foi e ainda é a que apresenta maior dificuldade de ser falada.

Concordamos com seu pensamento. Podemos perceber essa dificuldade ao pensarmos na Trindade. Quando falamos a respeito da relação entre Pai e Filho, essa fica bem clara e é algo sobre o qual falamos com relativa extensão, uma vez que há em nossa mente tanto a ideia de pai quanto a ideia de filho e como seria uma relação de intimidade desenvolvida entre essas duas pessoas.

Ao chegar na hora de falar do Espírito Santo temos, contudo, grandes dificuldades em dizer algo sobre sua Pessoa. Talvez, em decorrência de que não vejamos espíritos em nosso dia a dia. Na maioria das vezes em que falamos sobre espíritos o fazemos de forma representativa e essas diversas representações, quase sempre, são distorcidas, geralmente colocadas como um fantasma, ou um vulto branco vagando pelos ares, quase sempre remetendo a 
feições humanas quando espíritos humanos e feições animalescas quando se trata de algum animal.

Esse pequenos exemplos nos mostram que todas essas figuras de nosso imaginário não dão conta de falar de forma inteligível a respeito dessa categoria e, na história do discurso cristão, isso não se mostrou muito diferente. Diversas foram as dificuldades de se falar sobre o Espírito Santo. Com isso, podemos perceber a necessidade e o grande desafio que consiste em, dentro da teologia atual, propor uma pneumatologia que possa alcançar aos homens e mulheres de nosso tempo, fazendo sentido em sua existência e vivência no mundo.

Na tradição judaica é o termo ruah que aparece para falar a respeito da ação de Deus. Esse termo pode ser traduzido como sopro do ar, força viva no homem e força de vida de Deus, pela qual Deus age e faz agir em qualquer plano, seja espiritual ou fisco. No pensamento judaico, o Espírito de Deus é aquele que realiza o desígnio de Deus na história.

Nesse sentido, como bem aponta Congar:

Se o mundo de cultura grega pensa em categorias de substância, o judeu pensa em força, energia, princípio de ação. O espírito-sopro é aquele que age e faz agir e, quando se trata do Sopro de Deus, anima, faz agir para realizar o Desígnio de Deus. É sempre uma energia de vida. ${ }^{17}$

Já nos primeiros séculos da era cristã percebemos somente pequenas declarações, tais como "cremos em Espírito Santo", "e no Espírito Santo".

É somente no concilio de Constatinopla, em 381, que se tratará da divindade do Espírito Santo, no intuito de definir qual era a fé cristã frente às diversas heresias que surgiam naqueles períodos. Uma delas, desenvolvida por Aécio e Eunômio, dizia que, assim como o Filho é a primeira criatura do Pai, o Espírito é a primeira criatura do Filho.

Outra ideia que se tinha era dos trópicos egípcios que pregavam que o Espírito Santo possuía a divindade por nascimento, fazendo o Pai seu avô. Está implícita nessa ideia que o Espírito Santo não era gerado e, logo, não podia ser consubstancial ao Pai e ao Filho.

A terceira tendência era a dos pneumatômacos do Oriente (359-360) que consideravam o Espírito Santo inferior ao Pai e o Filho e, dessa forma, não

${ }^{17}$ CONGAR, Yves. Creio no Espírito Santo: revelação e experiência do Espírito. São Paulo: Paulinas, 2005, v.1, p. 18. 
devia ser glorificado juntamente com os outros dois. Foi Basílio de Cesaréia o grande responsável por, na luta contra os pneumatômacos, mostrar como na doxologia encontramos a divindade do Espírito. O Tratado sobre o Espírito Santo de Basílio foi determinante para que o Espírito pudesse ser afirmado pelo cristianismo, no Concílio de Constantinopla, como divino e também da mesma substância do Pai e do Filho.

$\mathrm{Na}$ Idade Média o pensamento que teve grande influência a respeito do discurso cristão sobre o Espírito Santo foi o de Joaquim de Fiore que, sentindo profundamente os defeitos da Igreja de seu tempo, acreditava em uma realização, nesse mundo, daquilo que esperamos para o além. Com isso em mente, dividiu a idade do mundo em três: 1) a idade do Pai que começa com Adão e é caracterizada pelo poder e a força em que os homens viveram como escravos da lei e como crianças; 2) a idade do Filho que começa com rei Ozias e frutifica a partir de Cristo, sendo caracterizada como a época dos clérigos que pregam a palavra de Deus; 3) a idade do Espírito Santo, a dos monges ou espirituais que começava com são Bento e que, à época de Joaquim de Fiore, estava para se manifestar definitivamente. Essa idade do Espírito seria um reino da liberdade e da paz universal.

No pensamento de Ratzinger, nas ideias de Joaquim de Fiore se iluminam as possibilidades e riscos da doutrina do Espírito Santo. Em suas palavras:

Em Joaquim há um signo orientador: sua prontidão para iniciar, aqui e agora, um cristianismo verdadeiramente espiritual e buscar esse cristianismo espiritual, não mais além da palavra, senão em sua mais completa profundidade ${ }^{18}$.

Ratzinger, porém, ressalta que a tese de Joaquim de Fiore se mostra superficial pelas múltiplas especulações, uma vez que o cristianismo espiritual, para nosso teólogo, é o cristianismo da palavra vivida. Um exemplo desse cristianismo espiritual, para nosso teólogo, pode ser percebido na vida de Francisco de Assis.

Contrariamente a Joaquim de Fiore, a pneumatologia de Joseph Ratzinger não pode e não deve ser pensada fora da sua relação com Jesus Cristo. Nesse sentido, toda pneumatologia ratzingeriana é cristológica.

Para Ratzinger, o Espírito mora na palavra e essa é a localização do

${ }_{18}$ RATZINGER, Joseph. El Dios de Jesucristo: meditaciones sobre Dios uno y trino. 2 ed. Salamanca: Sígueme, 1980, p.100. 
Espírito, que tem sua fonte em Jesus. Assim, quanto mais nos aproximamos de Jesus, mais nos aproximamos do Espírito Santo.

O Espírito se mostra a nós entrando no Filho e não fugindo Dele. Baseando-se em João 20, 19-23, que nos conta sobre a aparição de Jesus a seus discípulos depois de ressuscitado, e o sopro de Jesus concedendo o Espírito, Ratzinger quer nos fazer perceber que o Espírito é o sopro de Jesus que vem até nós quando nos deixamos insuflar por Jesus.

Ratzinger, seguindo a linha de Santo Irineu, defende que o Espírito está no começo e como signo indicador, apenas perceptível como guia do homem, conduzindo este ao Filho e, através do Filho, ao Pai. Nesse sentido, concorda com os primeiros padres da Igreja a respeito do Espírito Santo. Ele "consiste no comum, na unidade de Pai e Filho, é a unidade em pessoa. Pai e Filho são um entre si enquanto que vão além de si; no terceiro, na fecundidade da doação, são um único ser."19

Para Ratzinger, é claro nas Escrituras que o Espírito nunca é descrito em si mesmo, antes somente como esse vem aos homens. Assim, é pelas suas obras que conhecemos o Espírito Santo.

O Espírito Santo mora nas palavras de Jesus e essa palavra não pode ser possuída somente através da fala, antes observando-a e vivendo-a. " $\mathrm{Na}$ palavra vivida vive o que é a vida da palavra" 20 .

Mais acima podemos ver que Ratzinger relaciona Moisés com Jesus Cristo, em sua tentativa de mostrar Jesus como o profeta que deveria vir ao mundo. Contudo, enquanto Moisés conversava face a face diante de Deus, Jesus se colocava em relação filial e como Filho unigênito daquele a quem chama Pai, que é o Deus de Israel.

Com relação ao Espírito, Ratzinger, seguindo a tradição da igreja antiga, relê a subida de Moisés ao Monte Sinai fazendo relação à ascensão de Cristo e ao envio do Espírito Santo. Moisés sobe o Sinai e essa subida se mostra tanto como subida exterior quanto interior, expondo sua solidão diante de Deus e, como fruto dessa ascensão e solidão, o Espírito é trazido ao povo em forma de palavra orientadora. A palavra é trazida aos homens. Da mesma forma,

Jesus levou realmente a natureza humana, nossa carne, até a reciprocidade com Deus, a elevou através da nuvem da morte até à face de Deus. Desta

\footnotetext{
${ }^{19}$ Ibid., p. 102.

${ }^{20}$ Ibid., p. 103.
} 
ascensão veio o Espírito. O Espírito é fruto da vitória de Jesus, fruto de seu amor, fruto da $\mathrm{cruz}^{21}$.

Nisso, percebemos a estreita relação que Ratzinger estabelece entre pneumatologia e cristologia.

O Pai e Filho se movem em dinamismo presente e em pura doação mútua. Há, nesse dinamismo, uma fecundidade e essa fecundidade é sua própria unidade, sem se subtraírem ou se dissolverem um no outro, em outras palavras, ambos mantém sua identidade. Dessa fecundidade é que provém o Espírito Santo.

Da mesma forma que a identidade do Pai e do Filho não se confundem entre si, a do Espírito também não se confunde com a do Pai e a do Filho, antes, se demonstra como Espírito do único Deus em três pessoas, não só por não se apresentar separado e separável, antes, se ocultando dentro do Filho e do Pai.

Ao falar, o Espírito não expõe a si próprio, senão "o meu" de Jesus. Nesse sentido, seguindo a linha joanina, Ratzinger vê que a atividade do Espírito na história é o recordar das palavras de Jesus.

Esse recordar, que é a atividade do Espírito, se mostra, em Ratzinger, como verdadeira renovação. Nesse sentido, uma Igreja guiada pelo Espírito é aquela que sabe recordar as palavras de Jesus em sua maior profundidade.

Assim como o Filho se dá totalmente em genuína gratuidade e abertura, essa verdadeira generosidade e despojamento de si próprio, uma vez refletidos na Igreja, são uma marca do Espírito Santo nela.

\section{Considerações Finais}

Após esse percurso pelo pensamento de Ratzinger, parece-nos clara a constatação de que, em nosso teólogo, não é possível fazer uma pneumatologia isolada da cristologia e nem uma cristologia desvencilhada da pneumatologia. O Espírito é sempre o Espírito de Jesus e está em estreita relação com Ele, e o Filho é aquele que age na força do Espírito, se deixando guiar totalmente por ele em suas ações. Nesse sentido, como bem pontua José Vidal Taléns ${ }^{22}$, tratase também de uma cristologia pneumatológica.

\footnotetext{
${ }^{21}$ Ibid., p. 103.

22 TALENS, José Vidal. "Mirar a Jesús y al Hijo de Dios, hecho hombre para nuestra Redención. Aportación de J. Ratzinger a la Cristología contemporânea". In: MADRIGAL, Santiago. El pensamento de Joseph Ratzinger teólogo y papa. Madrid: San Pablo, 2009.
} 
O Espírito não se mostra somente como alguém alheio à história; está dentro da história de Jesus Cristo, caminhando juntamente com Ele, de tal forma que toda ação de Jesus é também uma ação do Espírito Santo.

O Espírito Santo continua a ação de Cristo no mundo, em sua abertura, amplitude e liberdade, visto ser idêntico à essa palavra que é pronunciada pelo Pai. Nesse sentido, é o Espírito que abre nossos olhos para que possamos contemplar e relembrar as palavras de Jesus que mostram que Ele era aquele a respeito de quem falaram os profetas.

Dessa forma, o acesso ao Jesus Real vem através de um viver como Jesus viveu, guiado pelo Espírito Santo, em total abertura de si para Deus e para o outro que vem até nós.

Passa a ser uma exegese a partir da vida, por meio Daquele que habita em nós e está em nós nos fazendo lembrar os passos de nosso mestre.

\section{Referências bibliográficas}

BENTO XVI, Papa. Os apóstolos e os primeiros discípulos de Cristo. São Paulo: Paulus, 2011, 182 p.

CONGAR, Yves. Creio no Espirito Santo: revelação e experiência do Espírito. São Paulo: Paulinas, 2005, v.1, 228 p.

CORDOVILLA, Ángel. "Siete tesis sobre el libro Jesús de Nazareth de Joseph Ratzinger - Bento XVI". Revista de Espiritualidad 266 (2008), pp. 123-144.

RATZINGER, Joseph. Dogma e anúncio. São Paulo: Loyola, 2007, 386 p.

RATZINGER, Joseph. El Dios de Jesucristo: meditaciones sobre Dios uno y trino. 2 ed. Salamanca: Sígueme, 1980, 106 p.

RATZINGER, Joseph. Introdução ao Cristianismo. 5. ed. São Paulo: Loyola, 2012, $268 \mathrm{p}$.

RATZINGER, Joseph. Jesus de Nazaré: do batismo no Jordão à transfiguração. São Paulo: Planeta do Brasil, 2007, 330 p.

RATZINGER, Joseph. Jesus de Nazaré: da entrada em Jerusalém até a Ressurreição. São Paulo: Planeta do Brasil, 2011, 271 p.

RATZINGER, Joseph. Ser Cristiano. Salamanca: Sígueme, 1967, 108 p.

SARTO, Pablo Blanco. La Teología de Joseph Ratzinger: una introducción. 2. Ed. Madrid: Palabra, 2011, 419 p. 
SCHWEITZER, Albert. A busca do Jesus histórico. São Paulo: Novo Século, 2005, $476 \mathrm{p}$.

TALENS, José Vidal. “Mirar a Jesús 'ver' al Hijo de Dios, hecho hombre para nuestra Redención. Aportación de J. Ratzinger a la Cristología contemporânea". In: MADRIGAL, Santiago. El pensamento de Joseph Ratzinger teólogo y papa. San Pablo. Madrid: 2009, 319 p.

Fabrício Veliq

Doutorando em Teologia pela Faculdade Jesuíta de Filosofia e Teologia de Belo Horizonte (FAJE) Belo Horizonte / MG - Brasil E-mail: fveliq@gmail.com

Recebido em: 11/04/16 Aprovado em: 19/05/16 